\title{
ManTool: Application as Manufacturing Tools for Resources Management based on GIS
}

\author{
Ika Arum Puspita ${ }^{1 *}$,Arrivan Dika Santosa ${ }^{2}$, Muhammad Agung Hambali $^{3}$, Faridhah Raehanisa Pribadi ${ }^{4}$, \\ Stevanus Yustiawan ${ }^{5}$
}

1,2,3,4,5 Telkom University

Jl. Telekomunikasi No. 1 , Bandung, 40258, Indonesia

*ikaarumpuspita@telkomuniversity.ac.id

\section{ARTICLE INFO}

Article history:

Received 01 April 2020

Accepted 22 January 2021

Published 31 January 2021

\begin{abstract}
IN ENGLISH
Competition in the textile industry is very high. Companies must be able to meet market needs by producing goods according to demand. In producing an item, it is necessary to design the amount of raw material required. This study aims to publish geographic information system (GIS) based application design as a tool in resource management. This application is named ManTool. ManTool can provide a reminder when raw material stocks run out. With this system, the company can order raw materials, and the production system continues to run well. This system is designed based on a Geographical Information System (GIS), it is easier for companies to determine which supplier of raw materials to choose. The method of making this system is by using the waterfall method. This method produces the right system because each stage is identified sequentially. The result of this research is a geographic information system-based application. With this application, the company will get a notification when the raw material runs out, and the company will get the right supplier's recommendation to buy raw material.
\end{abstract}

Keywords:

GIS; application, waterfall,

location, supplier.

\section{Introduction}

The textile industry sector in Indonesia is one of the most critical sectors for the Indonesian economy. In 2018 this sector became the largest employer in Indonesia, with 3.6 million people. In the same year, the industry contributed 13.22 billion dollars [1]. This achievement makes this sector one of the industry sectors' priorities and the mainstay [2]. However, this sector is not free from problems. One of the problems faced is a competition between local textile company products and foreign textile companies. This is the effects of several international agreements such as the ASEAN Free Trade Area (AFTA) since 2003, the ASEAN China Free Trade Area (ACFTA) in 2010, and the ASEAN Economic Community (AEC) in 2015 [3]. To stay afloat and keep going forward, the textile industry companies in Indonesia must develop and follow technological developments in the textile manufacturing process.

One of the companies in the textile sector is PT. XYZ. In undergoing the production process, companies often get a loss in profit due to fluctuating demand. It can be seen in figure 1. In some cases, fluctuating demand is proven to have substantial impacts on the production planning operation [4]. This results in difficulties in forecasting and leads to problems in the company's inventory. This situation led by the condition that company does not have proper monitoring process for resources like raw material and other supplies [5]. On the other hand, research was conducted to solve resource or inventory problems in the textile manufacturer by improving the warehouse management processor resource management process [6] brought by implementing resource management application. 


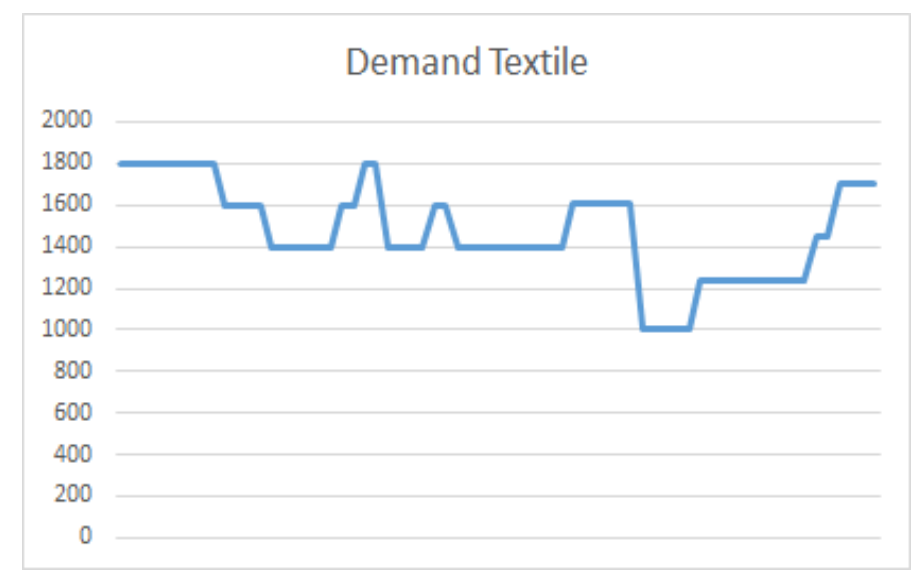

Fig. 1 - Textile demand in PT.XYZ

Geographic Information System (GIS) is a kind of location intelligence technology that supports the systematic collection, integration, analysis, and sharing of spatial data [7]. Fluctuating demand makes companies have to adapt to meet demand. Resource management is an important thing that companies must consider to carry out the production process. The data needed to manage resources can be analyzed using GIS. GIS has been applied in several applications, especially monitoring such as monitoring construction supply chain management [8], monitoring the storage and movement of materials [9]. GIS implementation for monitoring application, resource management application based on web and integrated will be brought up by waterfall development methodology based its advantages such as easy to implement, less time consuming, and its simplicity [10]. Using the waterfall method makes the application under the requirements. Each process is carried out by identifying the needs of the user at each stage.

This study will explain the GIS application design to manage resources. GIS application will store textile raw material inventory data, then manage and analyze it. The GIS application will display information on raw materials that will run out, when to order again, and recommend suppliers equipped with location data.

\section{Literature Review}

\subsection{Geographic Information System}

The use of GIS as a tool is increasing. This is due to the need for a system with real-time data, a simple user interface, and easy access to data. GIS is also used in various fields, one of which is in real-time hydrological models. The research presents a prototype, mobile-based model for flood warnings and forecasts [11]. GIS is also used in urban planning. The results show that the application of city planning and a system based on GIS technology can become the basis for urban planning [12]. GIS is also used in manufacturing. Currently, several companies in the GIS sector sell gis products for supply chain management purposes. There are also publications on GIS in the supply chain, by integrating the decision support system, simulation and optimization can be carried out for the supply chain [13]. This research is one of GIS uses in the supply chain, more specifically for resource management by displaying raw material stock data and supplier recommendations with location-based data.

\subsubsection{Definition}

A geographic information system (GIS) is a spatial based information system. We can enter data on this computer system, and then GIS will store, process, and display data related to maps showing the position of the earth's surface. The data displayed by GIS is in the form of a map containing data on roads, buildings, and vegetation. Data in the form of maps will make it easier for people to know, analyze, and understand patterns and relationships. Geographic information systems (GIS) are systems designed to capture, store, manipulate, analyze, manage and present all geographic data types. The main keyword in GIS is Geography, which means that GIS is a computer system that is different from other computer systems, with the difference that it has spatial properties. This means that geographic information systems refer to data that represent locations on earth.

Data in GIS consists of spatial data and data attributes. Spatial data displays an image of the object's location. Information attached to spatial data is called data attributes (tabular data). For example the location of a campus in a location is spatial data, then the campus data information is a data attribute. Examples of attribute data are campus name, campus address, profile, designated program, number of students, etc. [14]. 
GIS can process this second data then become a tool to assist decisions. GIS can be used to solve problems using spatial analysis. GIS has components consisting of people, software, hardware, and methods that are integrated to facilitate information to form maps.

\subsubsection{GIS Components}

GIS uses corresponding data related to space, including data related to events and things that occur in nature. Spatial data is not always in the form of soft files or stored in applications. However, there are times when this data is printed, such as traditional cartographic maps, log surveys, demographic statistics, geographical reports, and descriptions of field conditions. Technological advancements have influenced advances in the collection, classification, and accuracy of spatial data that have enabled more and more digital base maps to be available at different scales [15]. Here are the GIS components:

- Hardware

Hardware is the computer where GIS operates. GIS runs on various hardware types, from centralized computer servers to desktop computers used in standalone or network configurations.

- Software

GIS software functions as a tool used to store, analyze and display geographical information.

- People

GIS has limitations that cannot operate without someone managing the system. People act as those who manage the system and develop plans to implement it. GIS users are developers who make systems and users who use the system. Developers have technical specializations that design and maintain systems, users who use GIS to help them do their daily work.

- Method

The method used makes GIS successfully operate according to well-designed business plans and rules, unique models and operating practices for each organization.

- Data

Data is an essential component in GIS. Geographical data (spatial data) and tabular data (attribute data) can be obtained in two ways: collected alone or purchased from the data provider. GIS uses a DBMS to create and maintain databases to help organize and manage data.

\subsection{Resource Management}

Resources are the focus of management in an organization. Effective management of resources ensures there is no excessive allocation of resources in various projects. Peter Drucker writes about the need to focus resources, ignoring fewer promising initiatives for each new project taken, because fragmentation will hamper results.

In resource management, a management technique called resource smoothing is used. Resource smoothing can make effective use of resources by guaranteeing resources, reducing excess inventory, and anticipating shortages.

Data needed in this technique are the number of requests for various resources, demand forecasting based on a specific period, the configuration of the resources needed in the request, and the supply of resources, again estimated based on a specific period [16]. We can use Ishikawa diagrams to analyze the People, Money, Materials, and Machines needed. In short, resource management is the process of finding answers to questions - how to use available resources efficiently, effectively, and economically [17].

\subsection{Waterfall Model}

The Waterfall Model is the first model to be introduced. This model is straightforward to understand and use. This model has phase completion characteristics in stages; each phase must be completed first and then can start the next phase. In other words, there are no overlapping or intersecting phases. The Waterfall Model is the earliest SDLC approach used for software development [18].

In the "The Waterfall" approach, the entire software development process is divided into separate phases. The results of one phase act as input for the next phase in sequence. This means that each phase in the development process starts only if the previous phase is finished. The waterfall model is a sequential design process in which progress is seen to flow continuously downward (such as a waterfall) through the Conception, Initiation, Analysis, Design, Construction, Testing, Production / Implementation, and Maintenance phases [19]. Fig. $2 \mathrm{~s}$ the waterfall model. This model has five stages: 


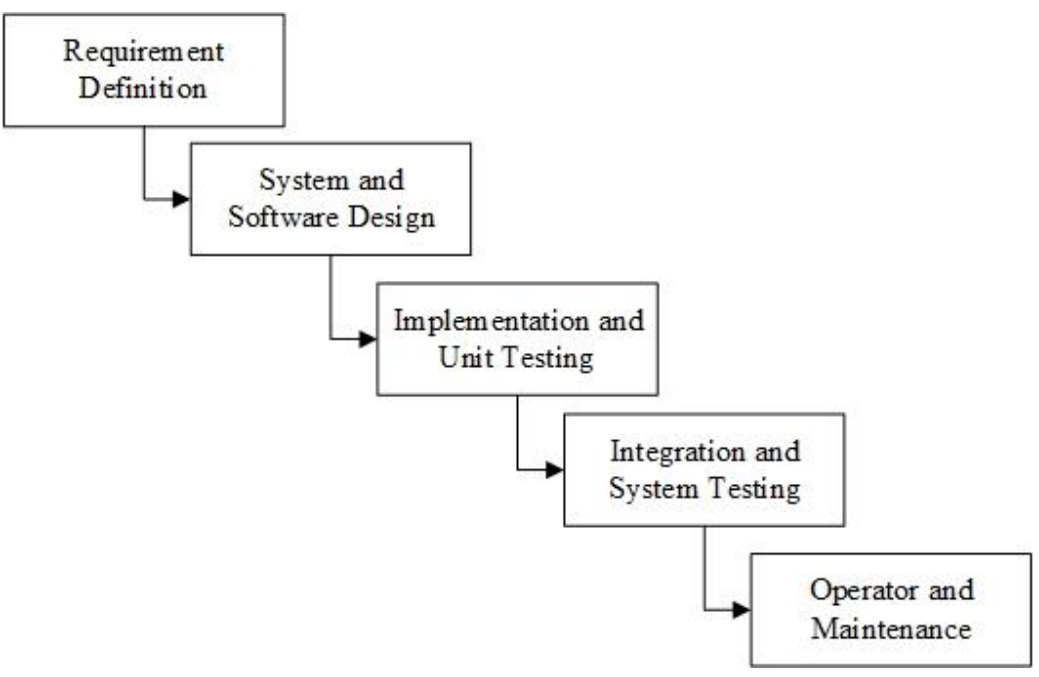

Fig. 2 - Waterfall Model

- Requirement

The first phase is requirements, in this phase by understanding what needs to be designed, function, purpose, etc. At this stage, it is necessary to specify the input, output, and the final product to be studied and marked.

- System Design

The specification of requirements that have been designed in the first phase is studied in this phase then the system design is prepared. System Design helps in determining hardware requirements and overall system architecture. In addition, at the start, coding for the software will be used.

- Implementation

After designing the system is complete made in the system design phase. Then the implementation phase begins. With input from system design, the system was first developed in a program called a small unit. This stage is the stage for starting to make an application in software. Every unit developed and launched to activate it is called Unit Testing.

- Integration and Testing

All units developed in the implementation phase are integrated into the system that is ready to be testing. Testing applications that have been made on the software to find out the existence of errors or not. System testing aims to prevent clients from facing problems with the use of the system. After functional and non-functional testing is carried out, the product is used in the customer's environment or released to the market.

- Maintenance

The maintenance phase is the face after the installation is complete. This phase supports modifications to the system or individual components to change attributes or improve performance. This modification arises because of changes in requests by customers, or defects found during system use. The client provides regular maintenance and support for the software developed.

\subsection{Software Tools}

To integrate tabular data with GIS-based location data using ArcGis software [20]. ArcGIS is used to create supplier location locations. In this study, the map used is the map of Bandung. With ArcGIS, data suppliers can request on maps to be analyzed and request to be geographic information. In addition to map data or spatial data, tabular data or attribute data can also be input in ArcGIS.

ArcGIS consists of desktop and web-based software. In this study, Web-based ArcGIS can be accessed by more than one user in different places. To support the display system that is easy to use and store data databases on ARCGIS integrated with PHP MySQL. The use of MySQL is included in the opensource category, can be used on various operating system platforms, has operators and full functions that support requests Select and Where in the request (request) and has an interface (interface) to the application and application language using the API function ( Application Programming Interface).

The data to be processed need to be structured modeled, with a data flow diagram. Data flow diagrams can be considered inverted Petri nets because their places correspond to the data memory semantics. By analogy, the semantic transitions of the Petri net and the data flow and the functions of the data flow diagram must satisfy the requirements [18]. By using software and tools, geographic information systems can be designed to input data, process and display it in a complete geographical location. 


\section{Research Method}

This study adopts the waterfall model as a system for developing its system development life cycle. This is because this method is commonly used to build an application or software. After all, it is simple, methodological, easy to understand, and easy to implement [18]. Even more, this model also uses sequential application development from design to maintenance. The waterfall method requires precise planning at the beginning of development. Although based on theory, this method does not allow iterations at each stage of development. In reality, it does not rule out the possibility of an iteration at each stage, but each stage's documentation is just one document [19]. The waterfall model stage is five stages in its development, i.e., requirement definition stage, system and software design, implementation and unit testing, integration and system testing, and operational and maintenance. Each phase in the waterfall model was run sequentially, where looping scheme was allowed in this study. Also, this study will only be applied until the system testing phase, not to the maintenance stage.

In the first step of this study, the definition of the requirement was based on the user's need and the purpose of application design. That the requirement analysis was conducted to identify the component of GIS and the data flow diagram of the resource management application. In the second step, the system was designed by designing the initial display design and application feature design. In the implementation step, the system's coding was done for the initial display and template for input form and list of each supplier and followed by coding features and dashboards of the monitoring supplier based on GIS. In the testing step, the system's testing was done for the initial display of the application and the functionality of the application features. In this case the testing activity was performed to find out whether the application is running with a bug or not. The test is carried out using the black box method so that it produces documentation testing. After the functionality has been tested, the next step is to do usability testing. Testing is carried out to the stakeholder.

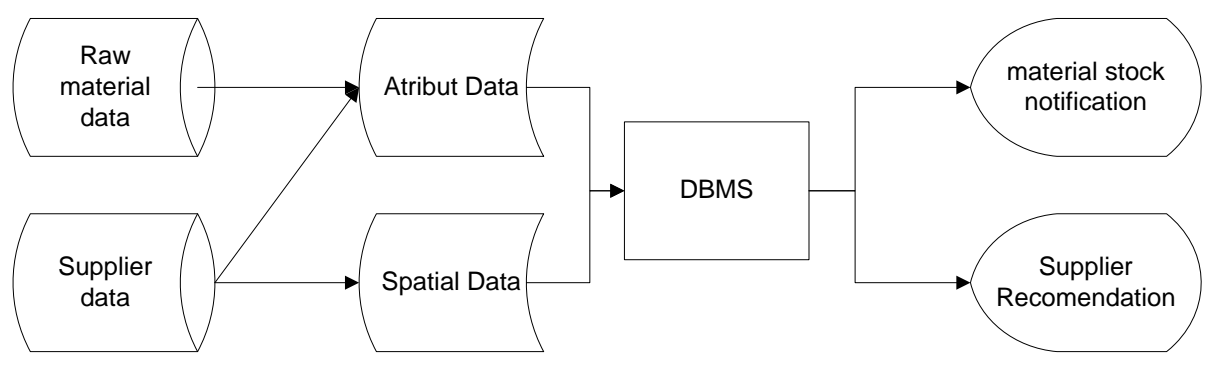

Fig. 3 - Overview of the GIS-based methodology

Fig. 3 shows an overview of the ManTool application. Raw material data consists of material name and quantity. Supplier data contains spatial data (map) and attribute data (location, name, raw materials provided). The data is processed until the amount of stock available in the warehouse is obtained. The data will be updated if any material is taken from the warehouse or added. When the amount of stock is at a specific limit, the application will display a notification of materials that must be ordered. This geospatial-based application provides an exciting youth when monitoring warehouse stock, this application also provides supplier recommendations that must be contacted when material stocks are at a specific limit.

\section{Result and Discussion}

\subsection{Requirement Definition}

\subsubsection{GIS Components}

An overview of the GIS components applied for application development:

- People

People involved as GIS components, namely the production section, and the warehouse section. This application will be used by warehouse personnel to monitor the stock of each supplier. If there is a notification, the warehouse staff will notify the procurement department to purchase raw materials. However, the raw material purchasing process is not included in the currently designed system.

- Data

Data is used to design GIS components. Spatial data used are supplier location maps, attribute data used are thread requirements data, raw material requirements data, and supplier data. Data requirements are user requirements that must be met in system design. This data is obtained by direct observation in the field and by interviewing the warehouse and production.

- Software

The software used for this research, namely ArcGIS, PHP MySQL 
- Hardware

The hardware used for this research is server and PC

- Objectives/Approach

The approach chosen was SDLC waterfall method.

\subsubsection{Data Flow Diagram}

The design of GIS applications in this study is related to resource management of yarn availability. This application can provide information related to the amount of yarn stock available at the warehouse, the type of yarn that must be ordered and supplier information. Data Flow Diagrams that are designed refer to the process of yarn stock management.

\section{DFD Level 0}

DFD level 0 only describes the system only. DFD level 0 only describes the flow of data from input to output from the application.

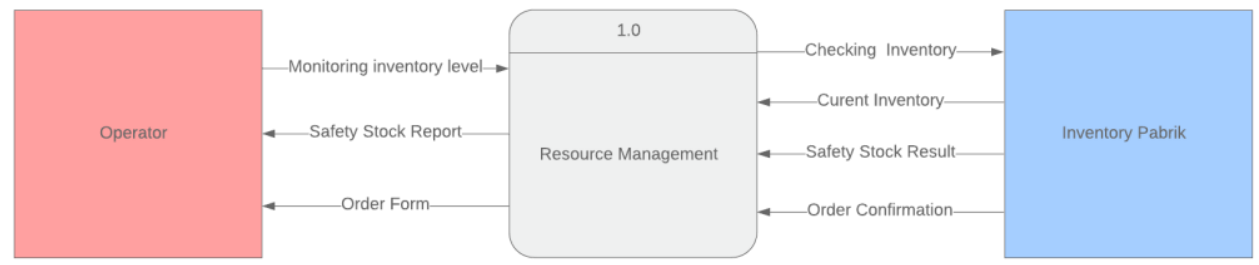

Fig. 4 - DFD Level 0

Fig. 4 shows DFD level 0 consisting of operators, resource management and factory inventory. The first process is the operator monitors inventory level through the resource management system, then the system checks the inventory contained in the factory inventory, and then the information is returned through the system to the operator. The information returned is a safety stock report and if there is a shortage of stock, an order will be made using the order form.

\section{DFD Level 1}

DFD level 1 describes the data flow that is more complicated in each process which then forms the data store and data flow.

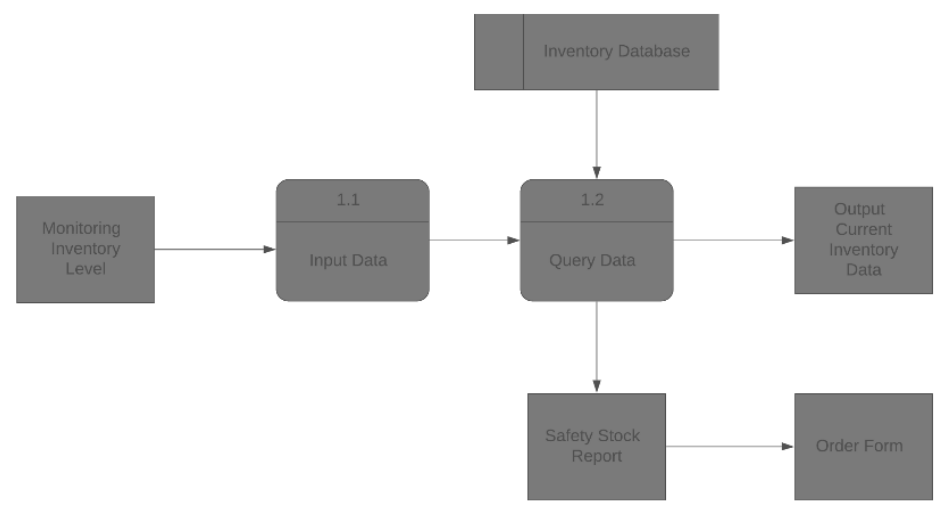

Fig. 5 - DFD Level 1

Fig. 5 shows DFD Level 1 of the resource management system created. The first stage is monitoring inventory level by inputting data, then querying data from the database and issuing outputs in the form of current inventory, and safety stock reports which will then be continued into an order form. 


\subsection{System and Software Design}

After the requirements phase is complete, then enter the design stage. At this stage the application description will be designed.

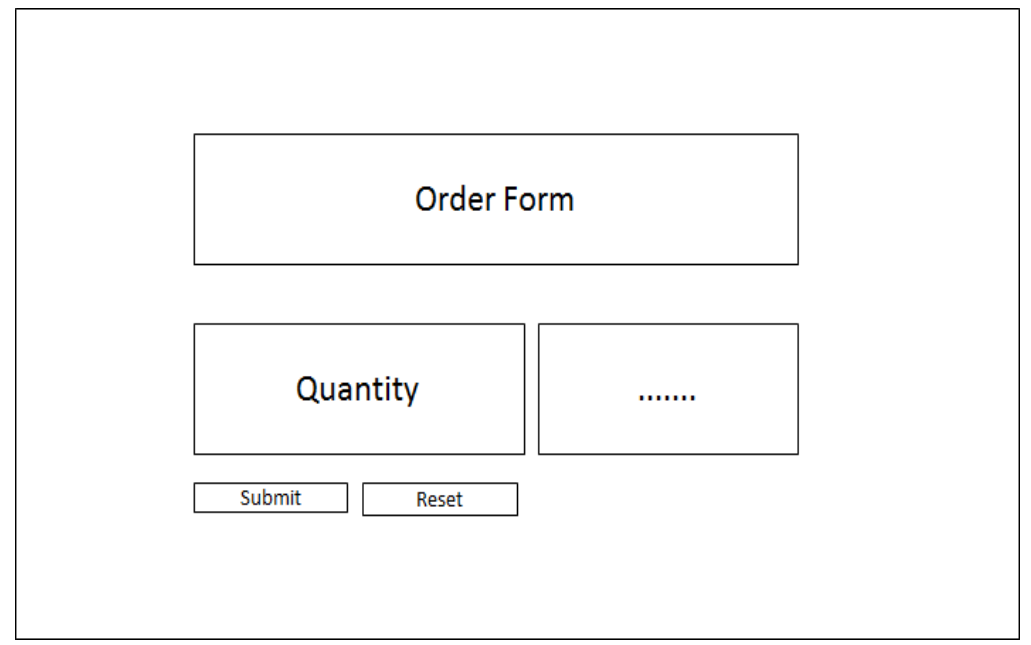

Fig. 6 - Design of Order Form

Fig.6 shows the draft form for ordering raw material to the supplier when the raw material from one of the suppliers has reached safety stock. Admin can immediately determine the amount of material needed and can immediately submit the form so that the order can be processed.

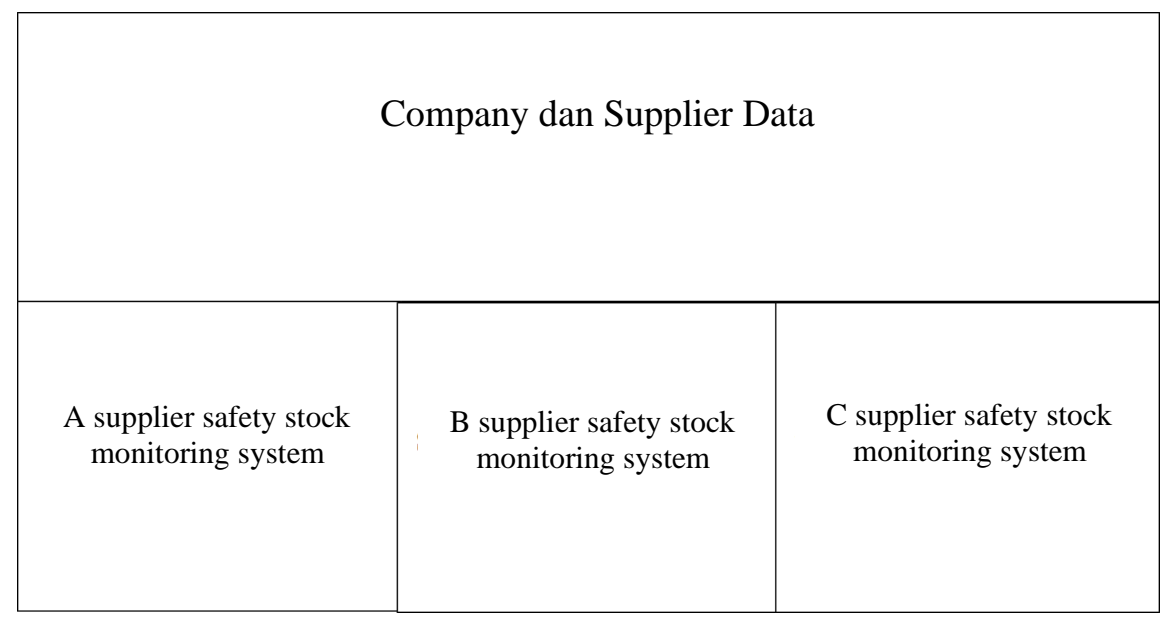

Fig. 7 - Resources Monitoring System Design

Fig. 7 shows the design system for monitoring the company's safety stock will display a map of the company's location and also the location of the supplier, later if there are raw materials that reach the safety stock limit, the system will provide a report for the appeal to immediately place an order for a particular supplier.

\subsection{Implementation and Unit Testing}

At the implementation stage the researchers built the system using ArcGis Software. By using a supplier map in stock monitoring makes this application provide easier information for users so that it helps in making decisions faster. Fig. 8 shows the initial appearance of the application design that has been made shows the results as in the picture above by showing the option to make transactions with supplier A, supplier B, or supplier C 


\section{Home Supplier A Supplier B Supplier C}

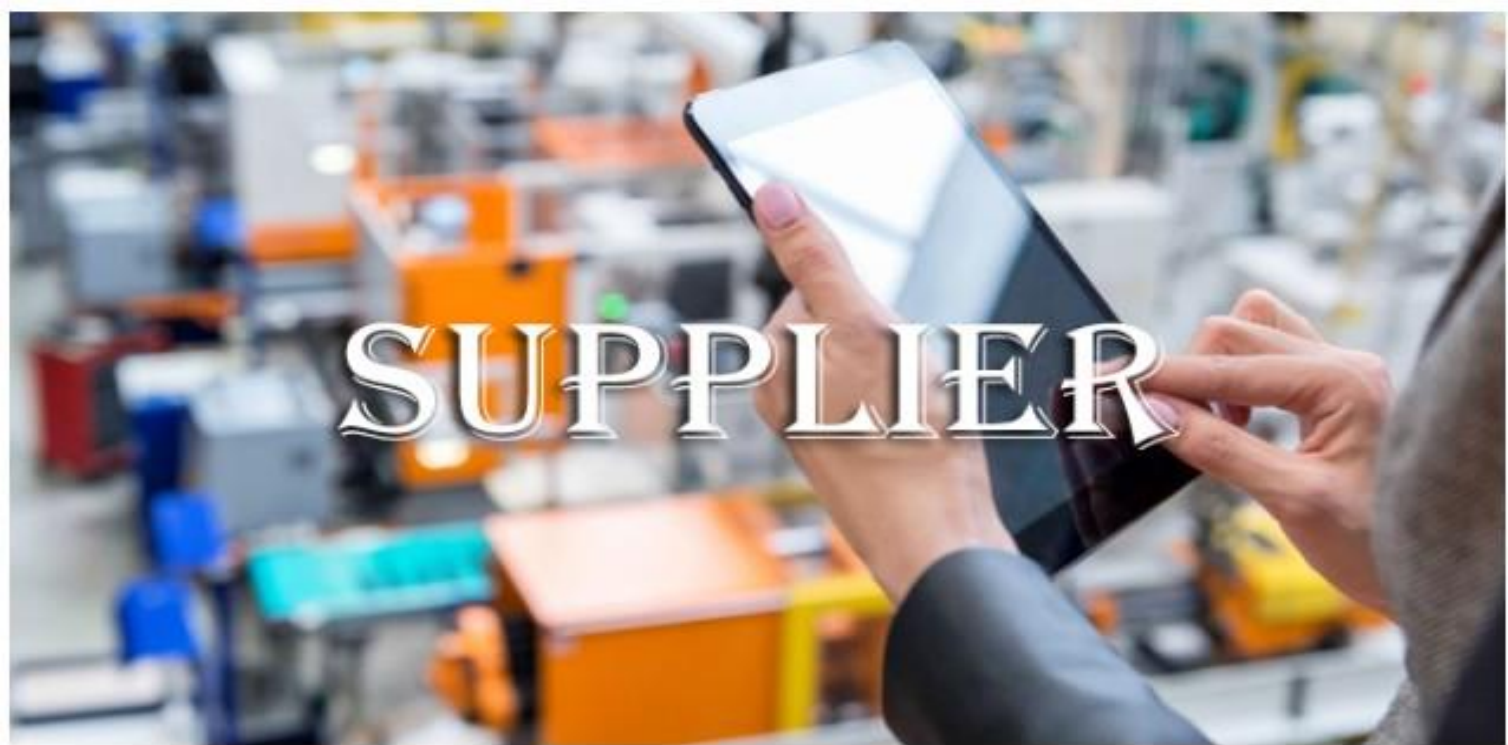

Data Supplier (Final Project) by Group 1

(9) All Rights Reserved

Fig. 8 - Home of Resources Monitoring System

Figure 9 shows the results of the design for those who know the list of orders to certain suppliers. Admin can immediately determine the amount of material needed and can also change or delete data orders that are wrong or not so to be processed.

\section{Data Supplier for Application}

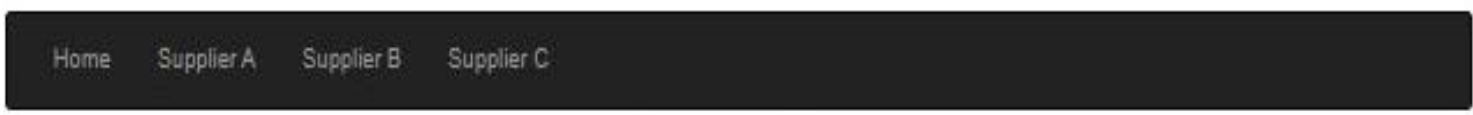

Back to Form Supplier A

\section{List of Data Supplier A}

\begin{tabular}{|l|l|l|}
\hline No ID & Quantity & \\
\hline 49 & 20 & Delete \\
\hline 50 & 20 & Delete \\
\hline 51 & 20 & Delete \\
\hline 52 & 20 & Delete \\
\hline 53 & 20 & Delete \\
\hline 54 & 450 & Delete \\
\hline
\end{tabular}

\section{Data Supplier (Final Project) by Group 1} (9)All Rights Reserved

Fig. 9 - Order List 


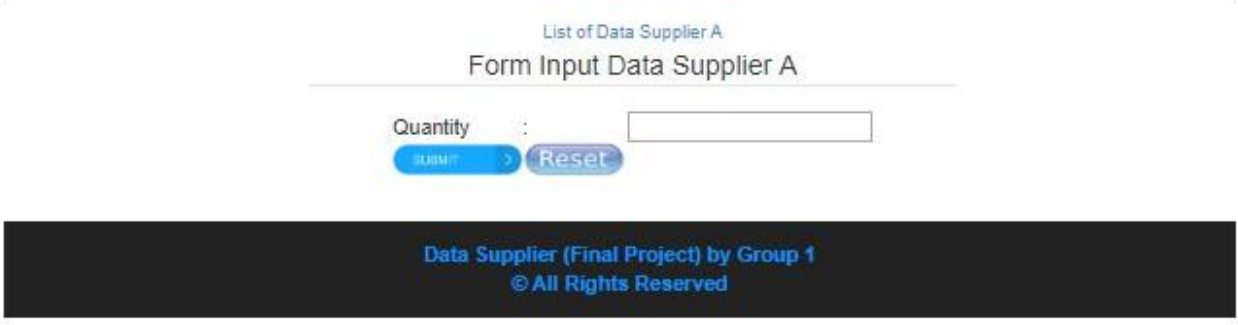

Fig. 10 - Order Form

The order form is shown in the fig. 10, it shows the results of the design to order raw material to the supplier when the raw material from one of the suppliers has reached safety stock. Admin can immediately determine the amount of material needed and can immediately submit the form so that the order can be processed.

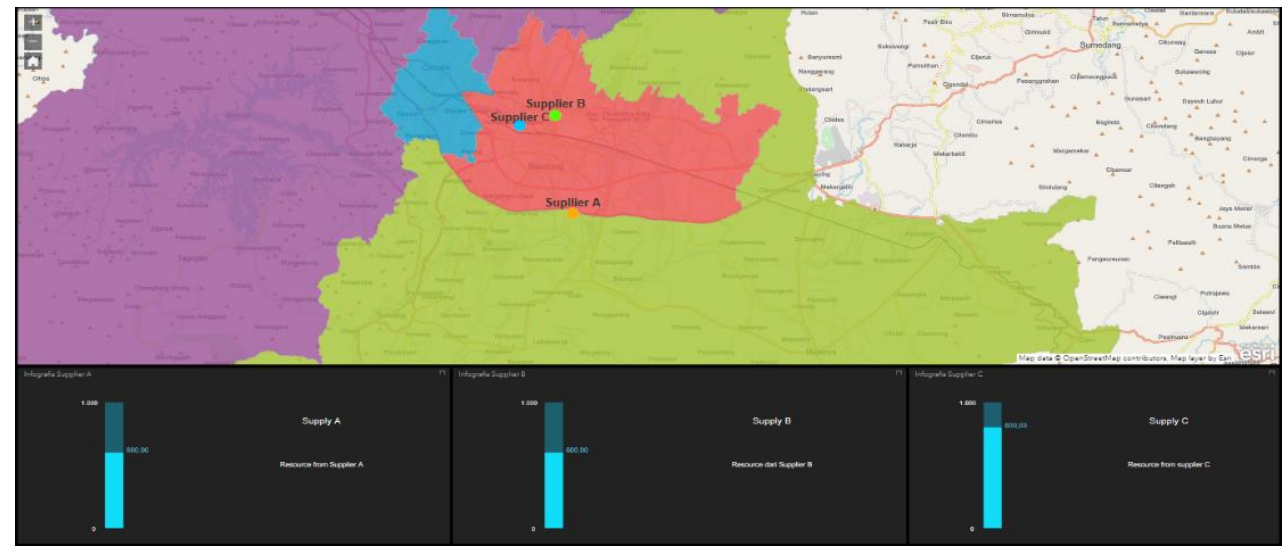

Fig. 11 - Resources Monitoring System

Following is the appearance of the application that has been made. Fig. 11 shows coordinates for each supplier and the company's factories located in different regions. Application design results show the amount of material available in each type of material obtained from three suppliers. When one of the material reaches the safety stock, the system will provide a report and a warning to immediately order new material to the required supplier.

This research design is a resource management application that can monitor supply from several suppliers and the locations of these suppliers. What will be monitored is the company's factory inventory's safety stock to order raw materials somewhat to be more monitored because if it has passed below the safety stock limit, the system will give the warning to reorder raw materials.

\subsection{Integration and System Testing}

System testing is done to find out the error in making an application. In the GIS application designed in this study, researchers conducted 4 types of testing.

Table 1 - System Testing

\begin{tabular}{lcc}
\hline Scenario & Expected result & Status \\
\hline $\begin{array}{l}\text { Open the application for all the user } \\
\begin{array}{l}\text { User production enter the number } \\
\text { of requirements for the supplier }\end{array}\end{array}$ & $\begin{array}{c}\text { Go to dashboard page } \\
\text { Thmber of requirements need } \\
\text { stored in the database }\end{array}$ & Valid \\
$\begin{array}{l}\text { User production see the list of } \\
\text { requirements for the supplier }\end{array}$ & $\begin{array}{c}\text { Display the list of requirement needs } \\
\text { for the supplier }\end{array}$ & Valid \\
$\begin{array}{l}\text { User inventory (warehouse) } \\
\text { monitoring the requirements need } \\
\text { for production }\end{array}$ & $\begin{array}{c}\text { Display the reporting of requirement } \\
\text { needs for production from the database }\end{array}$ & Not Valid \\
\hline
\end{tabular}


Application that can monitor supply from several suppliers and suppliers' locations. In its implementation, researchers conducted a system testing to determine the suitability of applications developed with the company's needs. The picture above shows the results of several scenarios. The system designed still cannot automatically display reports for requirements needs, so the application must still be repaired to run according to the company's expectations and needs. Also, the system designed has fulfilled three other scenarios:

- All users can use the application.

- The user can input the number of material needs.

- The user can see a list of needs for orders to the supplier.

\section{Conclusion}

After conducting research and application development, it can be concluded that the system or application is expected to have good potential to detect and prevent a shortage of raw materials in the company to carry out the production process. Deficiencies that often occur in the production process can be minimized, so the company can get more leverage to meet customer demands. This research has shown the GIS application design in manufacturing. Companies can use GIS applications to monitor the raw material stock of each supplier. This application can also display notification of raw materials that reach the minimum stock limit. However, this application still has limitations and needs further development to display requirements for production reports.

\section{Disclaimer}

The authors whose names are written certify that they have no conflict of interest.

\section{References}

[1] Kemenperin, (2019). Lampaui 18 Persen, Industri Tekstil dan Pakaian Tumbuh Paling Tinggi.

[2] A. Susanto et al., (2017). PEMILIHAN STRATEGI PENINGKATAN DAYA SAING INDUSTRI TEKSTIL DENGAN PENDEKATAN ANP-BOCR.

[3] Nurhasanah, N., Tanjung, W. N., Ripmiatin, E., Wulandari, S. A., Qibtiyah, M., and Meliantika. (2016). Enhancing competitiveness of ready made garment small-medium enterprises through logistics performance measurement using SCOR method,” 2016 2nd Int. Conf. Ind. Mech. Electr. Chem. Eng. ICIMECE 2016, pp. 123-126.

[4] Jobrich, W. and Promsivapallop, P. (2018). Demand fluctuation in the fine dining restaurant industry: patterns , impacts , and management strategies ( A case study in Phuket ), vol. 13, no. 1, pp. 27-32.

[5] Journal, I. and Mandya, E. (2016). Monitoring and Controlling of Smart Equipments in Manufacturing Industry, vol. 4, no. 3, pp. 96-100.

[6] Phupattarakit, T. and Chutima, P. (2019). Warehouse Management Improvement for a Textile Manufacturer,” 2019 IEEE 6th Int. Conf. Ind. Eng. Appl. ICIEA 2019, pp. 235-239.

[7] Zhu, X. (2014). GIS and urban mining," Resources, vol. 3, no. 1, pp. 235-247.

[8] Agrawal, R. and Goyal, A. (2016). Warehousing location optimisation for a supply chain using differential evolution and GIS," Int. J. Serv. Comput. Oriented Manuf., vol. 2, no. 3/4, p. 245.

[9] Jadid, M. N. (2016). Application of GIS-Based Construction Engineering: An Electronic Document Management System. Int. Sch. Sci. Res. Innov., vol. 10, no. 9, pp. 1144-1152.

[10] Chandra, V. (2015). Comparison between Various Software Development Methodologies,” Int. J. Comput. Appl., vol. 131, no. 9, pp. 7-10.

[11] Alsabhan, W. and Love, S. (2011). Platforms and viability of mobile GIS in real-time hydrological model," Journal of Systems and Information Technology, Vol. 13 Iss 4 pp. 425 - 444.

[12] Luan, Q. and Zhang, L. (2017), "Design and Application of Urban Planning and Location System Based on GIS Technology", Open House International, Vol. 42 No. 3, pp. 5-9.

[13] Zhang, F., Johnson, D., Johnson, M., Watkins, D., Froese, R., and Wang, J. (2016). Decision support system integrating GIS with simulation and optimisation for a biofuel supply chain. Renewable Energy 85, 740-748.

[14] Marwick, B., Hiscock, P., Sullivan, M., and Hughes, P. (2017). Landform boundary effects on Holocene forager landscape use in arid South Australia," Journal of Archaeological Science.

[15] Foresman, T. (1997). The History of GIS (Geographic Information Systems): Perspectives from the Pioneers. (Prentice Hall Series in Geographic Information Science), 1st edition ed., Prentice Hall PTR, p. 416.

[16] Project Management Institute (PMI). (2014). A Guide to the Project Management Body of Knowledge, Third ed., Pennsylvania: Project Management Institute (PMI).

[17] Project Management Institute (PMI). (2018). A Guide to the Project Management Body of Knowledge, Fourth ed., Pennsylvania: Project Management Institute (PMI). 
[18] Kramer, M. (2017). Best Practice in Systems Development Lifecycle: An Analysis Based on the Waterfall Model,"Review of Business \& Finance Studies, vol. 9, pp.77-84.

[19] Bruza, P. D. and van der Weide, T. P. (1990). Assessing the quality of hypertext views. pp. 6-25.

[20] Asghari, F.B., Mohammadi, A. A., Dehghani, M. H., Yousefi, M. (2018). Data on assessment of groundwater quality with application of ArcGIS in Zanjan, Iran. Data in Brief 18, 375-379.

[21] Demarco, T. (1979). Structured Analysis and System Specification, New York: Yourdon Press.

[22] Soesanto, R. P., Rizana, A. F., and Andrawina, L. (2019). Design of Reporting, Evaluation, and Monitoring Application for Student Organization in University. International Journal of Innovation in Enterprise System, vol. 3, no. 01, pp. 53-57. 